\title{
Análise microestrutural, composicional e dureza das cerâmicas indígenas do sítio arqueológico Caninhas, SP
}

\section{(Microstructural, compositional and hardness characterization of the archaeological indigenous ceramics of Caninhas, SP, Brazil)}

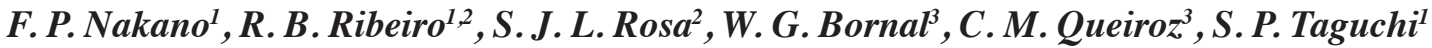 \\ ${ }^{1}$ Departamento de Engenharia de Materiais - DEMAR, Escola de Engenharia de Lorena - EEL/USP, Pólo Urbo- \\ Industrial, Gleba AI-6, CP 116, Lorena, SP 12600-970 \\ ${ }^{2}$ Departamento de Desenho Industrial, Faculdades Integradas Teresa D’Ávila - FATEA, Rede Salesianas, Av. \\ Peixoto de Castro 539, Vila Zélia, Lorena, SP 12606-580 \\ ${ }^{3}$ Núcleo de Arqueologia do Vale do Paraíba, Fundação Cultural de Jacarehy, Av. José Cristovão Arouca 40, \\ Centro, Jacareí, SP 12327-707
}

\begin{abstract}
Resumo
Cerâmicas arqueológicas possuem uma infinidade de dados sobre a dinâmica social e cultural dos indígenas do sítio Caninhas, SP. A superfície de fratura apresenta gradiente de cor, do ocre ao cinza escuro, quando da superfície para o centro da peça. Este aspecto é decorrente dos gradientes de temperatura gerados durante a queima da peça cerâmica, de forma que na superfície a combustão dos compostos orgânicos é completa (coloração mais clara) e na parte interna é incompleta (coloração mais escura). Foram realizadas análises composicionais por difração de raios X e mapeamento por EDS, sendo identificadas as fases ilita, quartzo e lutecita (região ocre) e ilita, quartzo, alumina-hidratada e lutecita (região cinza escura). Os resultados de EDS confirmaram a presença dos elementos químicos das fases identificadas por difração de raios X. As análises microestruturais por microscopia óptica e eletrônica por varredura sugerem a presença de raízes e restos de cerâmicas sinterizadas nas peças indígenas. Os resultados de dureza Vickers mostraram o quanto frágeis e heterogêneas são as cerâmicas arqueológicas, alcançando aproximadamente 203 HV (grãos de sílica) e 16 HV (matriz cerâmica).
\end{abstract}

Palavras-chave: cerâmicas arqueológicas indígenas, microestrutura, propriedades mecânicas, análise composicional.

\begin{abstract}
Archaeological ceramics contain many data about social and cultural indigenous site Caninhas, SP, Brazil. The ceramics present a gradient of color (ochre to dark gray), when from the surface to the center of the piece. This behavior is associated with thermal gradients in ceramic pieces during the sintering process, resulting in a complete combustion of organic compounds at the piece surface (clear color) and incomplete burning inside the piece (dark color). Phase composition was analyzed by X-ray diffraction (XRD) and mapping by EDS, identifing the illite, quartz and lutecite phases (ochre region) and illite, quartz, hydrated alumina and lutecite phases (dark gray region). The results of EDS confirmed the chemical elements identified by X-ray diffraction. Optical microscopy and scanning electron microscopy analyses suggested the presence of roots and scrap of sintered pieces in indigenous ceramics. The Vickers hardness values showed the fragility and heterogeneity of archaeological ceramics, reaching approximately $203 \mathrm{HV}$ in the grains of silica and $16 \mathrm{HV}$ in the ceramic matrix.
\end{abstract}

Keywords: archaeological indigenous ceramics, microstructure, mechanical properties, compositional analysis.

\section{INTRODUÇÃO}

A descoberta do sítio arqueológico em Canas, SP, denominado sítio arqueológico Caninhas, composto por estruturas funerárias, estruturas de combustão e diversos objetos de uso cotidiano de populações indígenas que habitaram o local, abre um considerável leque de possibilidades no que diz respeito a estudos relacionados à História e conseqüentemente à memória vinculada ao patrimônio da região. A categoria do sítio arqueológico de Canas é unicomponencial, de natureza pré-colonial, cuja tribo possivelmente é Tupiguarani devido características dos utensílios como formação por acordelamento e pinturas geométricas na cor vermelha, branca e preta, com pequenas alterações de estilo, forma, textura e dimensões [1-3]. Existiam quatro possíveis unidades habitacionais, com vestígios de material predominantemente cerâmico e lentes de carvão, aparecendo até $40 \mathrm{~cm}$ de profundidade. As estruturas de sepultamento situavam-se fora das ocupações habitacionais indicando padrões culturais de uso do espaço, e em diferentes áreas sugerindo uma diferenciação e hierarquização do espaço. As urnas continham cerâmicas 
ao invés de corpos, indicando possíveis oferendas, cujo conteúdo ainda não se encontrava compactado. A pintura presente nos fragmentos e tigelas recuperadas se encontra em bom estado de conservação, indicando que a provável ocupação da aldeia tenha acontecido entre os séculos XIV e XVI, mas é necessário maiores investigações para determinar toda esta gama de possibilidades [1]. Os fragmentos cerâmicos arqueológicos apresentaram diferentes tipos de superfícies: corrugada, ungulada, lisa e escovada. Corrugada: caracterizada pela "ação lateral do dedo sobre a superfície cerâmica, pressionando uma parte da argila, por arraste, e formando uma crista de forma semilunar como resultado do acúmulo de argila arrastada" [4]; Ungulada: consiste na expressão decorativa da ação frontal da unha, na forma de um arco, com sentido e formato de quem aplica [4]. Lisa: consiste no alisamento com o auxílio de uma pedra, madeira ou a própria mão de quem produz, deixando a superfície lisa [4]. Escovada: consiste na perfuração com os dedos ou algum tipo de material que deixam linhas paralelas na superfície da cerâmica [4]. A vasilha cerâmica carrega consigo dados referentes ao local de produção, manufatura, utilização e descarte ou abandono [5].

As argilas (argilo-minerais), matéria-prima para produção de cerâmicas, pertencem à classe do filo-silicatos e são essencialmente silicatos hidratados de alumínio, de composições diversas podendo conter teores de ferro, cálcio, magnésio e potássio. São os principais constituintes dos solos e se formam pela decomposição direta (em condições superficiais) de silicatos primários (olivinas, piroxênios, anfibólicos, micas, feldspatos, etc.), formadores das principais rochas ígneas, metamórficas e sedimentares. É comum encontrarem-se argilas misturadas com quantidade variável de quartzo finamente pulverizado. Seus tipos principais são ilita, caolinita e montmorillonita [6].

Para uma maior eficiência da compreensão da dinâmica social e cultural dos indígenas da região, por parte dos arqueólogos, a engenharia de materiais tornase uma ferramenta importante, pois os dados obtidos das propriedades dos fragmentos certamente contribuem para uma classificação mais precisa. O estudo da microestrutura, da composição e da dureza do material recolhido do sítio arqueológico traz informações que podem tanto confirmar, como complementar e mesmo contradizer as informações de fontes bibliográficas.

A difratometria de raios $\mathrm{X}$ (DRX) pode ser uma ferramenta para detectar as temperaturas de queima das cerâmicas arqueológicas, quando comparadas com cerâmicas sinterizadas em diferentes temperaturas [8]. No entanto, a comparação dos difratogramas de diversas amostras pode ir além da inferência de temperatura, pode-se estimar a qualidade da cerâmica, por meio da identificação de compostos cristalinos e o grau de cristalinização dos compostos. A técnica pode também ser um caminho para identificação das fontes de argilas utilizadas [7-8].

A microestrutura da cerâmica, obtida por análises por microscópio eletrônico de varredura (MEV) e microscópio óptico (MO) pode auxiliar na identificação de diferentes componentes na massa cerâmica. Um desses componentes podem ser materiais antiplásticos antropomórficos (materiais que diminuem a plasticidade da argila, introduzido pelo homem) adicionados ou mesmo naturalmente encontrados nas argilas da região. Exemplo destes são as fibras vegetais, conchas, ossos e grãos de quartzo [9].

As cerâmicas arqueológicas algumas vezes são materiais compósitos que têm suas propriedades mecânicas alteradas dependendo da composição, temperatura de queima, quantidade de defeitos, geometria, dentre outros. Sendo assim, é de interesse determinar a influência de aditivos na dureza das cerâmicas com o intuito de inferir sobre o desenvolvimento tecnológico das civilizações pré-coloniais da região [9]. A dureza Vickers à temperatura ambiente varia de 5 a $7 \mathrm{GPa}(\sim 509,8$ a 713,8 HV $)$ para sílica fundida e de 9 a $11 \mathrm{GPa}(\sim 917,7$ a $1121,7 \mathrm{HV})$ para o cristal de quartzo [10]. Esse tipo de análise, por ser destrutivo, é aplicado a um número reduzido de amostras que possam ser cortadas no tamanho adequado e sejam representativas do grupo ao qual pertencem [11].

Este trabalho tem como objetivo analisar microestrutura, composição e propriedades mecânicas das amostras com superfície lisa encontrada no sítio arqueológico Caninhas, SP.

\section{EXPERIMENTAL}

A superfície externa (branca) e interna (lisa) da amostra lisa foi analisada por difração de raios X, microscopia óptica, microscópia eletrônica de varredura e dureza Vickers:

Análise das fases cristalinas: uma pequena amostra da superfície de parte ocre, e também da parte cinza escuro das cerâmicas, foi fragmentada a pó passante em peneira de 300 mesh e caracterizada quanto às fases cristalinas em um difratômetro de raios $\mathrm{X}$ Rich-Seifert com radiação $\mathrm{CuK}$ $(\lambda=1,5418 \AA)$ filtrada com $\mathrm{Ni}$, na faixa $2 \theta=10-90^{\circ}$, passo angular $0,05^{\circ}$ e tempo de contagem $2 \mathrm{~s}$. As fases foram identificadas com as fichas JCPDS.

Microestrutura: as amostras foram embutidas a frio em resina Serefix e, posteriormente, foram lixadas e polidas em uma politriz automática Phoenix 4000. Foram utilizadas lixas de carbeto de silício de $\# 180$ a 4000 . A morfologia das cerâmicas foi analisada em microscópio óptico com analisador de imagem Leica DM-IRM, e também microscópio eletrônico de varredura Leo $1450 \mathrm{VP}$, com detectores de elétrons secundários (para avaliar a morfologia e tamanho médio das partículas e dos grãos) e detectores de elétrons retroespalhados (para avaliar a distribuição dos possíveis agregados na composição das cerâmicas). Pelo fato de cerâmicas não serem condutoras, foram metalizadas com aproximadamente $5 \mathrm{~nm}$ de ouro.

Análise composicional: foi feita por espectroscopia de energia dispersiva (EDS) ao longo do perfil da cerâmica indígena. O objetivo de realizar o mapeamento de EDS é 
avaliar o gradiente de composição das cerâmicas indígenas.

Ensaio de dureza: a amostra, previamente embutida, lixada e polida, foi submetida a indentação Vickers em microdurômetro Buehler. Foi feita uma amostragem bastante significativa (mais de 30 ensaios) para determinação do desvio padrão.

\section{RESULTADOS E DISCUSSÃO}

A Fig. 1 mostra o gradiente de cor da amostra sendo perto da superfície cor ocre e, em seu interior, cor cinza escuro.

A Fig. 2 apresenta as fases cristalinas determinadas por difração de raios $\mathrm{X}$ da amostra de superfície lisa parte ocre, com a presença de lutecita $\left(\mathrm{SiO}_{2}\right)$, quartzo $\left(\mathrm{SiO}_{2}\right)$ e illita $\left[\mathrm{K}_{0,7} \mathrm{Al}_{2}(\mathrm{Si}, \mathrm{Al})_{4} \mathrm{O}_{10}(\mathrm{OH})_{2}\right]$.

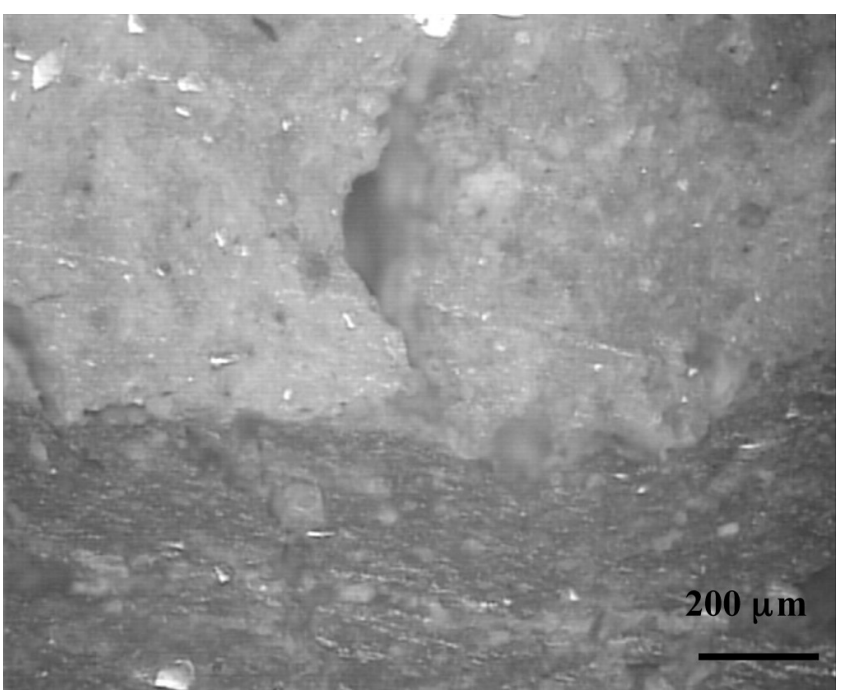

Figura 1: Micrografia óptica mostrando o gradiente de cor da amostra de superfície lisa.

[Figure 1: Optical micrograph showing a gradient of color of even surface sample.]

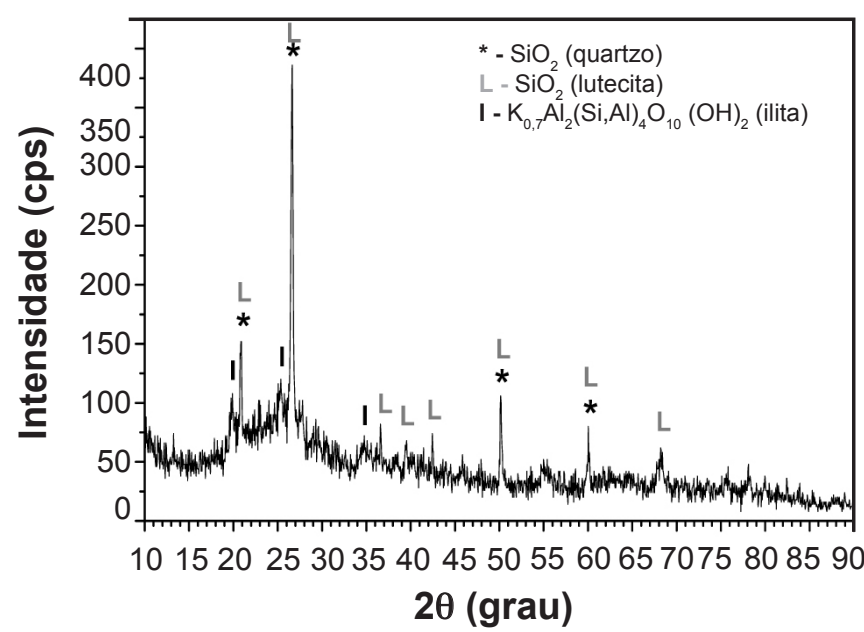

Figura 2: Difratograma de raios $\mathrm{X}$ da amostra de superfície lisa (parte ocre).

[Figure 2: X-ray diffraction pattern of ochre region of even surface sample.]
A Fig. 3 apresenta as fases cristalinas determinadas por difração de raios $\mathrm{X}$ da amostra de superfície lisa parte cinza escuro, com illita $\left[\mathrm{K}_{07} \mathrm{Al}_{2}(\mathrm{Si}, \mathrm{Al})_{4} \mathrm{O}_{10}(\mathrm{OH})_{2}\right]$, lutecita $\left(\mathrm{SiO}_{2}\right)$, quartzo $\left(\mathrm{SiO}_{2}\right)$, alumina hidratada $\left(\mathrm{Al}_{10} \mathrm{O}_{15} \cdot \mathrm{H}_{2} \mathrm{O}\right)$ e uma fase amorfa.

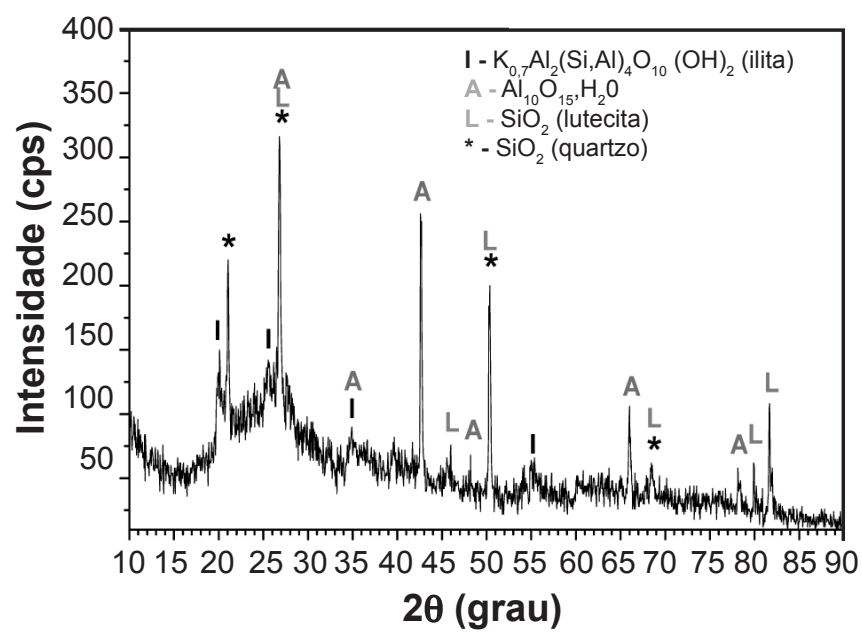

Figura 3: Difratograma de raios $\mathrm{X}$ da amostra de superfície lisa (parte cinza escuro).

[Figure 3: X-ray diffraction pattern of dark gray region of even surface sample.]

A Fig. 4a mostra as micrografias das amostras de superfície lisa parte ocre, onde se pôde observar uma grande presença de trincas, poros e três fases: 1 (grãos de cor cinza escuro), 2 (grãos de cor cinza claro) e 3 (matriz). $\mathrm{Na}$ micrografia da Fig. $4 \mathrm{~b}$ pode-se observar um composto orgânico não decomposto durante a queima, possivelmente raízes, compondo a microestrutura da parte ocre da amostra de superfície lisa.
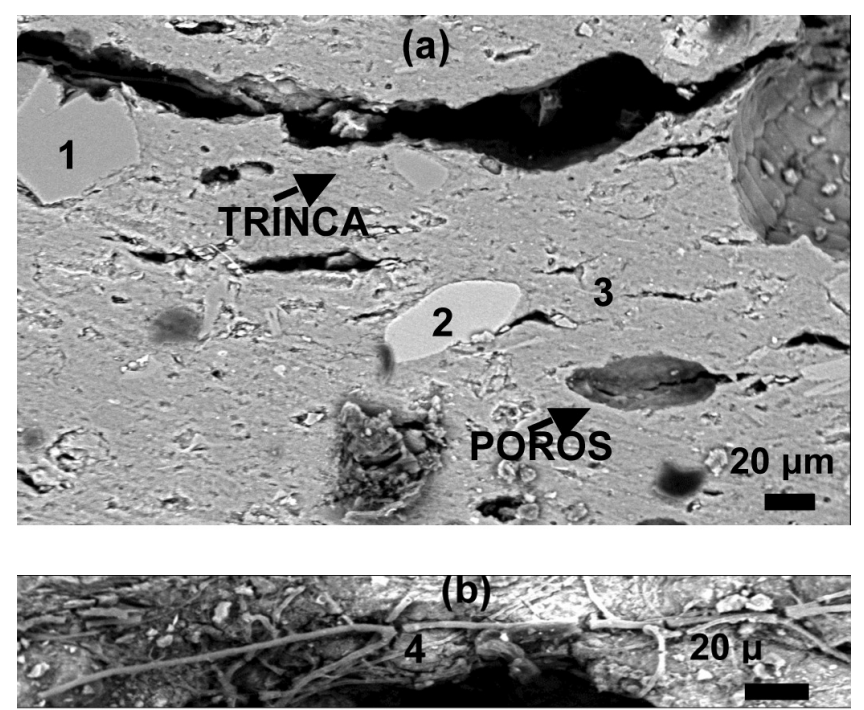

Figura 4: Micrografia obtida por microscopia eletrônica de varredura no modo retroespalhado da amostra de superfície lisa: (a) parte ocre; (b) composto orgânico.

[Figure 4: SEM micrograph obtained on backscattering mode of even surface sample: (a) ochre region; (b) organic composition.] 
A Fig. 5 mostra a análise composicional por EDS, que geralmente é uma análise semiquantitativa, realizada na parte ocre das amostras de superfície lisa.

A análise de EDS foi feita em 4 regiões diferentes: a região 1 apresenta os elementos $\mathrm{Si}$ e $\mathrm{O}$; na região 2 têm-se $\mathrm{O}, \mathrm{Al}$, Si e K; na matriz encontra-se $\mathrm{O}, \mathrm{Al}$, Si e Fe, indicado na Fig. 4a; e na região 4, da Fig. 4b, têm-se C, O, Al, Si.

A Fig. 6 mostra a micrografia da parte cinza escuro das amostras de superfície lisa. Podem-se observar trincas e poros, e também 3 fases distintas denominadas região 1, 2 e 3 .
A Fig. 7 mostra a análise composicional por EDS da parte cinza escuro das amostras de superfície lisa, apresentando os mesmos elementos identificados na parte ocre da amostra, porém em quantidades pouco diferentes.

Comparando os resultados de difração de raios X, EDS e microestrutura verifica-se, tanto na amostra de superfície lisa parte ocre, como na amostra de superfície lisa parte cinza escuro, que na região 1 (cor cinza) têm-se os grãos de quartzo $\left(\mathrm{SiO}_{2}\right)$ e a região 2 (cor branca) refere-se à ilita. Já na região 3 (matriz) há uma mistura que tem como constituintes
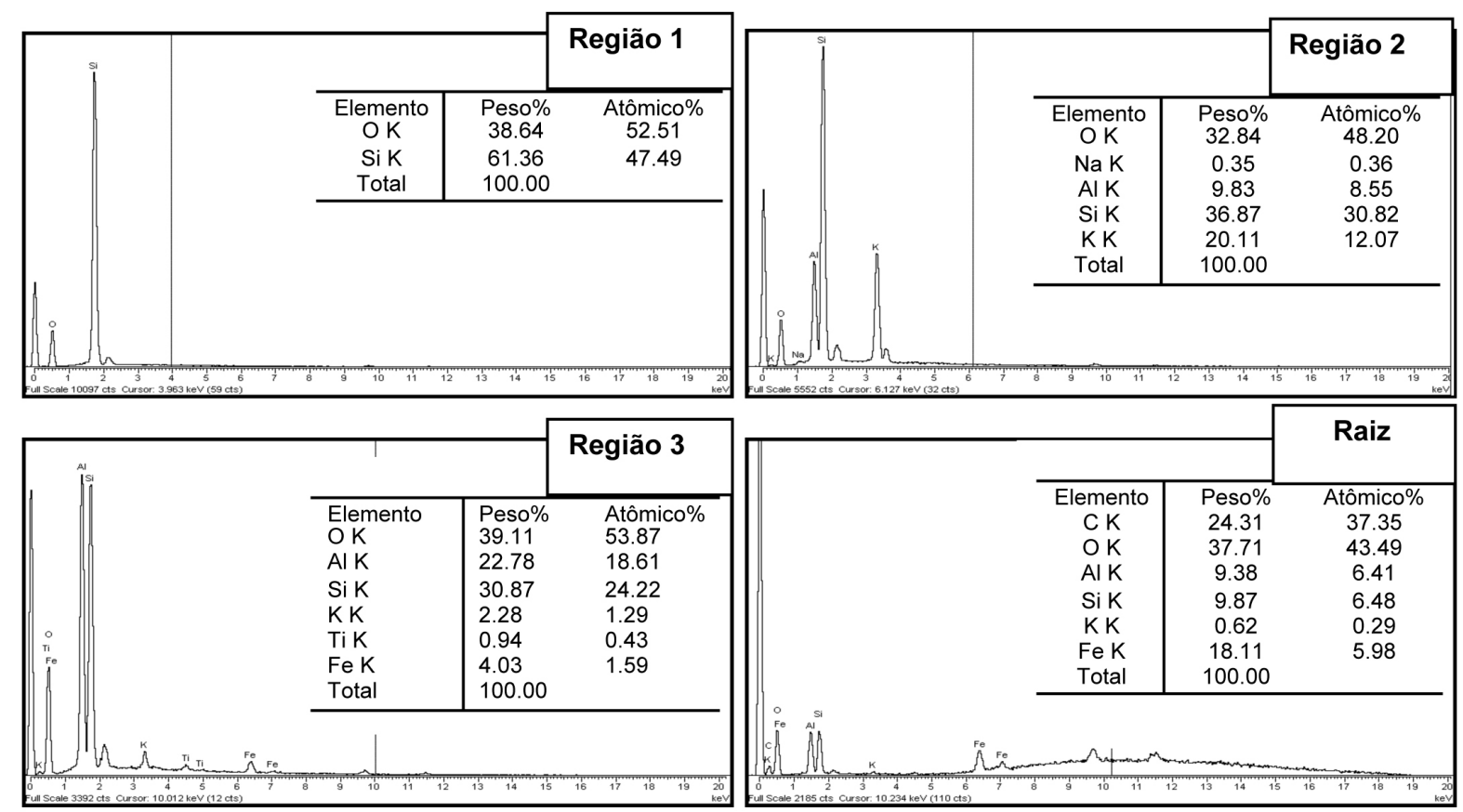

Figura 5: Análise composicional por EDS da parte ocre da amostra de superfície lisa.

[Figure 5: EDS compositional analysis of ochre region of even surface sample.]

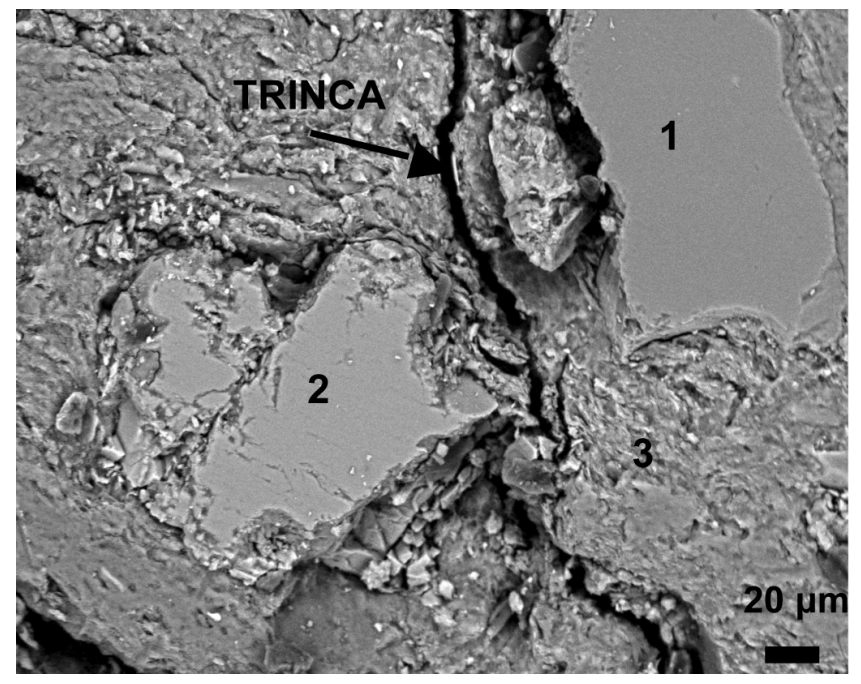

Figura 6: Micrografia obtida por microscopia eletrônica de varredura no modo retroespalhado da amostra de superfície lisa parte cinza escuro.

[Figure 6: SEM micrograph obtained on backscattering mode of dark gray region of even surface sample.]
O, Al, Si e Fe para a amostra de superfície lisa parte ocre, só sendo identificadas a fase lutecita $\left(\mathrm{SiO}_{2}\right)$ por DRX, porém para a parte cinza escuro pode identificar a presença de uma combinação de alumina hidratada, lutecita e compostos orgânicos ou carbonatos.

As durezas encontradas para as partes ocre e cinza escuro das amostras de superfície lisa foram, respectivamente, de $15,53 \pm 5,05 \mathrm{HV}$ e $17,35 \pm 5,87 \mathrm{HV}$. A Fig. 8 mostra a microestrutura da indentação Vickers na qual se pode observar poros que dificultaram visualização da indentação, o que justifica o alto valor do desvio padrão. Devido à elevada heterogeneidade das cerâmicas arqueológicas foi realizado um mapeamento em relação à dureza da cerâmica de superfície lisa. Após mapeamento percebeu-se uma grande quantidade de grãos de quartzo aderidos à massa cerâmica. Assim, foi feita também a medida de dureza para estes grãos de quartzo aderidos ao corpo cerâmico, tanto da amostra de superfície lisa parte ocre como para parte cinza escuro. A dureza Vickers encontrada, para os grãos de quartzo, é de $203 \pm 17,7 \mathrm{HV}$ que está bem abaixo dos valores encontrados na literatura (aproximadamente 917,7 a 1121,7 

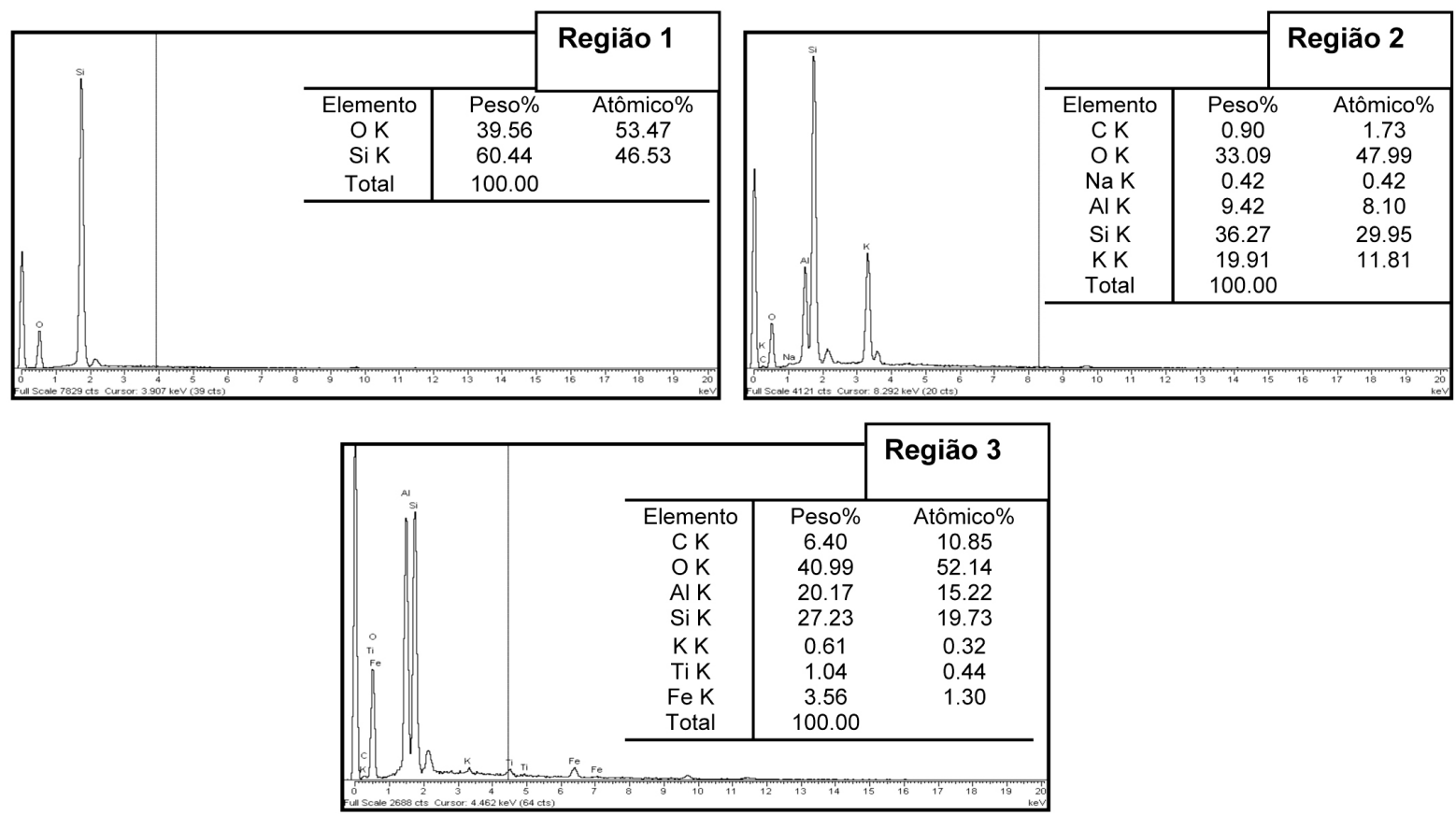

Figura 7: Análise composicional por EDS na amostra de superfície lisa parte cinza escuro. [Figure 7: EDS compositional analysis of dark gray region of even surface sample.]

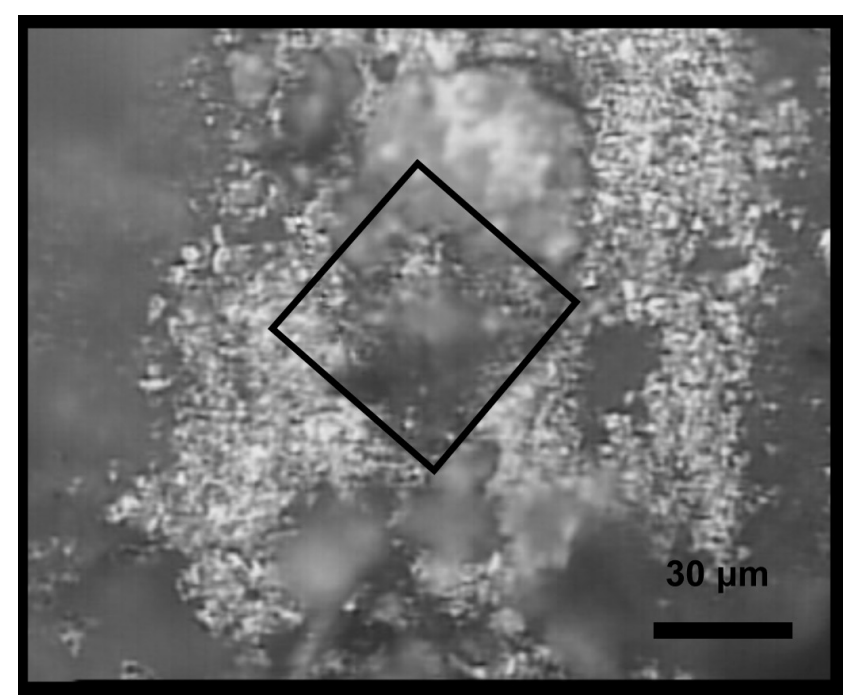

Figura 8: Micrografia obtida por microscopia óptica de uma indentação Vickers na amostra de superfície lisa.

[Figure 8: Optical micrograph of Vickers indentation of even surface sample]

HV). Considerando que os grãos de quartzo estão envoltos por uma matriz que possui dureza muito menor, é natural que ocorra interferência no resultado.

\section{CONCLUSÕES}

Pelas micrografias pode-se confirmar a presença de aditivos antiplásticos antropomórficos nas cerâmicas, caracterizadas pela presença de raízes e grãos de quartzo. Os antiplásticos podem ter sido adicionados às cerâmicas para melhorar suas propriedades mecânicas. Com a análise composicional por EDS observou-se que na matriz da parte ocre da amostra de superfície lisa, o elemento carbono não foi encontrado, entretanto, na matriz da parte cinza escuro da amostra de superfície lisa o elemento carbono apareceu significativamente, indicando que a parte externa (ocre) foi sujeita a um melhor tratamento térmico que o interior (cinza escuro). Embora as cerâmicas apresentassem muitos poros e trincas, conseqüentemente baixos valores de dureza, estas foram utilizadas como utensílio indígena, e permaneceram por centenas de anos, algumas intactas, outras quebradas, no sítio arqueológico de Canas, SP.

\section{AGRADECIMENTOS}

Ao CNPq pela bolsa de IC e auxílio pesquisa (Procs. 121418/2008-1 e 481703/2008-0) e ao grupo de trabalho deste projeto (R. B. Ribeiro, C. C. Matos, S. J. L. Rosa e alunos de ensino médio de Canas, SP, integrantes do projeto).

\section{REFERÊNCIAS}

[1] W. G. Bornal, C. M. Queiroz, Relatório das escavações do sítio Caninhas (2005) 36.

[2] F. S. Noelli, Revista da USP 44 (1999-2000) 218.

[3] P. A. M. Ribeiro, in Escritos sobre Arqueologia, Eds.: P. A. M. Ribeiro, C. O. I. Nunes, Fundação Universidade Federal do Rio Grande, Porto Alegre, RS (2001).

[4] F. La Salvia, J. P. Brochado, Cerâmica Guarani, Posenato Arte e Cultura, Porto Alegre, RS (1989).

[5] I. A. T. Bona, J. E. S. Sarkis, V. L. R. Salvador, A. L. 
R. Soares, S. C. Klamt, Análise Arqueométrica de Cerâmica Tupiguarani da Região Central do estado do Rio Grande do Sul, Brasil, usando fluorescência de raios X por dispersão de energia (EDXRF), Quim. Nova 30, 4 (2007) 785.

[6] J. A. Batista, A utilização de substâncias minerais pelos povos indígenas. Breves comentários, Anuário Inst. Geociências, UFRJ, Rio de Janeiro, RJ (1999) 100 p.

[7] C. Jácome, Estudo dos materiais utilizados na cerâmica pintada Tupiguarani de Minas Gerais, Diss. Mestrado em Artes Visuais Escola de Belas Artes, UFMG, Belo Horizonte, MG (2006) 46p.

[8] M. Alves, Análise cerâmica: estudo tecnotipológico, Tese Dr. em Cerâmica Pré-histórica, Faculdade de Filosofia,
Letras e Ciências Humanas, USP, S. Paulo, SP (1988) 258. [9] U. P. Rodrigues, F. M. Felicíssimo, R. C. Bicudo, P. V. Silva Jr., J. L. Peixoto, Estudos Arqueométricos de Cerâmicas Indígenas Pré-Coloniais do Pantanal Sulmatogrossense, in Resumos $24^{\mathrm{a}}$ Reunião Anual SBQ, Poços de Caldas, MG (2001) p. 162.

[10] Eng. Mater. Handbook: Ceramic and glasses, ASM International, NY, EUA (1991).

[11] G. Vekinis, V. Kilikoglou, Mechanical performance of quartz-tempered ceramics: part II, Hertzian strength, wear resistance and applications to ancient ceramics, Archaeometry 40, 2 (1998) 281.

(Rec. 24/04/2009, Rev. 05/08/2009, Ac. 30/10/2009) 